\title{
Proline Absorption and SGK1 Expression are Inhibited in Intestinal Tis7 Transgenic Mice
}

\author{
Jianyun Lu ${ }^{\mathrm{a}}$ Amy M. Garcia ${ }^{\mathrm{a}}$ Taylor Geisman ${ }^{\mathrm{a}}$ Derek Wakeman ${ }^{\mathrm{b}}$ Brad W. Warner ${ }^{\mathrm{b}}$ \\ Elzbieta A. Swietlickia Marc S. Levin ${ }^{a, d}$ Deborah C. Rubin ${ }^{a, c}$ \\ aDepartment of Medicine, Division of Gastroenterology, Washington University School of Medicine, \\ Saint Louis, ${ }^{b}$ Department of Surgery, Division of Pediatric Surgery, Washington University School \\ of Medicine, Saint Louis, 'Department of Developmental Biology, Washington University School of \\ Medicine, Saint Louis, 'Medical Service VA St. Louis Health Care System, Saint Louis, MO, USA
}

\section{Key Words}

Amino acid absorption • Tis7/IFRD1 • Short bowel syndrome $\bullet$ Intestine $\bullet$ Adaptation

\begin{abstract}
Background/Aims: Expression of the transcriptional co-regulator tis7 is markedly increased in the adaptive small intestine in a mouse model of short bowel syndrome. Transgenic mice with enterocytic overexpression of tis7 (tis $7^{\text {tg }}$ ) have accelerated triglyceride absorption, with increased adiposity yet reduced skeletal muscle mass. To further explore this phenotype, we examined whether tis7 also regulates amino acid and carbohydrate absorption. Methods: Small intestinal glucose and amino acid uptake were quantified in wild type (WT) and tis $7^{\text {tg }}$ mice. Amino acid transporter expression was assessed by qRT-PCR and immunoblot. Apical cell surface transporter expression was quantified by cell surface biotinylation. Results: Active glucose uptake rates were unchanged. Uptake of proline but not leucine was significantly reduced in tis $7^{\text {tg }}$ vs. WT jejunum. Expression of serum and glucocorticoid-induced kinase 1 (SGK1), a solute carrier activator, was inhibited in tis $7^{t g}$ jejunum. Apical membrane expression of the proline transporter SLC6A20 was reduced in tis $7^{\text {tg }}$ jejunum. Conclusions: Tis7 overexpression in enterocytes inhibits proline uptake, associated with decreased expression of activated SGK1 and reduced cell surface expression of SLC6A20. Consistent with the observed tis $7^{\text {tg }}$ phenotype, tis 7 overexpression increases triglyceride absorption but has adverse effects on the uptake of selected amino acids. Tis7 has pleiotropic effects on nutrient absorption.
\end{abstract}

\section{Introduction}

(C) 2016 The Author(s)

Published by S. Karger AG, Basel

Loss of small bowel following surgical resection for treatment of disorders including Crohn's disease, intestinal ischemia, trauma or necrotizing enterocolitis may result in short bowel syndrome. Patients with short bowel syndrome may become dependent on parenteral nutrition, with its attendant morbidity, mortality and high health care costs [1-5]. Following resection, the remnant intestine has an innate, albeit limited ability to adapt morphologically

Deborah C. Rubin, M.D., AGAF,

Prof. of Medicine and Developmental Biology
Division of Gastroenterology, Washington University School of Medicine, 660 South Euclid Avenue Box 8124, St. Louis Missouri 63141, (USA)

Tel. +1 314-362-8935, Fax +1 314-362-8959, E-Mail drubin@dom.wustl.edu 
and functionally following resection. This response is characterized by enhanced crypt cell proliferation, crypt depth and villus height [1-4]. There are few therapies that enhance small bowel surface area and function following resection [1-4]. The mechanistic basis of this adaptive response is being investigated in order to facilitate the discovery of novel therapeutic targets. Complicating these studies in humans is the recognition that there is remarkable heterogeneity in the adaptive response among patients [6].

We have previously shown that expression of the immediate early gene tis7 (12-0-tetradecanoylphorbol-13-acetate-induced sequence 7) is markedly increased in enterocytes during the adaptive response to massive small bowel resection in a mouse model of short bowel syndrome [7, 8]. Tis7 is a transcriptional co-regulator [9] that binds to DNA binding proteins and the Sin3 complex to modulate HDAC activity [10]. Tis7 is the mouse homologue, pheochromocytoma cell-4 (PC4) the rat homologue and interferonrelated developmental regulator 1 (IFRD1) the human homologue. Tis7/IFRD1 has been implicated in the regulation of cell proliferation, differentiation, and cellular responses to stress and tissue damage [9]. To further elucidate its role in gut adaptation we generated transgenic mice with intestinal enterocytic overexpression of tis7 (tis $7^{t g}$ ) [11]. These mice have a phenotype that mimics some of the metabolic changes found in parenteral nutrition dependent patients with short bowel syndrome. For example, tis $7^{t g}$ mice have increased body fat yet reduced skeletal muscle mass, similar to what has been observed in these patients [11]. These mice also exhibit accelerated triglyceride absorption, and more rapid and proportionately greater weight gain on a high fat diet [11]. However, when fed a chow (low fat) diet, tis $7^{\text {tg }}$ mice have significantly lower body weight compared to WT littermates, despite consuming the same amount of chow [11]. These observations suggested that intestinal absorption of other nutrients in addition to lipids is altered in $t i s 7^{\text {tg }}$ mice. Since tis 7 functions as a transcriptional co-regulator [9], this might occur by regulating the expression of a wide range of genes involved in the digestion [12,13] and uptake [14] of dietary proteins and carbohydrates. In the present study, we addressed the hypothesis that tis7 regulates protein and/or carbohydrate absorption, by investigating glucose and amino acid uptake in tis $7^{\text {tg }}$ compared to WT intestine, using in vitro everted sleeve techniques [15].

Glucose uptake is primarily mediated by the sodium-glucose co-transporter 1 (SGLT1) and to a lesser extent, by the glucose transporter 2 (GLUT2) [16]. We chose to first study the uptake and absorption of neutral amino acids including L-proline and leucine [17], because mice that are null for the neutral amino acid cotransporter Slc6A19 have a similar phenotype to the $t i s 7^{\text {tg }}$ mouse, with significantly lower body weight compared to WTs when fed a chow diet [18]. Our data showed that proline uptake into tis $7^{\text {tg }}$ intestine was significantly reduced compared to WT intestine, whereas glucose and leucine uptake was unchanged. Reduced proline absorption was associated with decreased apical cell surface expression of SLC6A20, and decreased expression of the activated (phosphorylated) form of serum and glucocorticoid-induced kinase 1 (pSGK1), a known activator of a subset of ion channels and solute carriers [19]. Our data suggest that tis7 plays a novel role in the regulation of intestinal nutrient uptake. Increased enterocytic tis 7 expression results in increased triglyceride absorption but has adverse effects on the uptake of selected amino acids.

\section{Materials and Methods}

\section{Materials}

Sources: The anesthetic isoflurane was from Butler Schein Animal Health (Dublin, OH). Radiolabeled probes $\mathrm{D}-\left[{ }^{14} \mathrm{C}(\mathrm{U})\right]$ glucose (D-glc), L- $\left[{ }^{14} \mathrm{C}(\mathrm{U})\right]$ proline (L-pro), L- $\left[{ }^{14} \mathrm{C}(\mathrm{U})\right]$ leucine (L-leu) and radiolabeled markers L- $\left[1-{ }^{3} \mathrm{H}\right]$ glucose, $\left[1,2-{ }^{3} \mathrm{H}\right]$ PEG 4000, were from American Radiolabeled Chemicals, Inc (St Louis, MO). Tissue solubilizer and Ultima Gold liquid scintillation cocktail were from Perkin-Elmer (Waltham, MA). Oligonucleotide primers were from Integrated DNA Technologies Inc. (Coralville, IA). Pierce Cell Surface Protein Isolation Kit and 100X Halt Protease and Phosphatase Inhibitor Cocktail were from Thermo Fisher Scientific Inc. (Rockford, IL). TRIzol, DNA-free kit, Super-Script II reverse transcriptase and 2x Sybr 


\section{Cellular Physiology Cell Physiol Biochem 2016;38:1532-1543

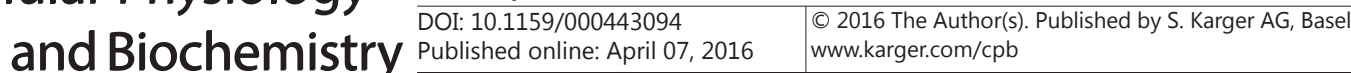

Lu et al.: Reduced Proline Absorption in Tis7 Transgenic Mice

Green Master Mix were from Life Technologies (Carlsbad, CA). Anti-pThr256-SGK (sc16744R), anti- $\beta$-actin (sc47778), anti-SGLT1 (sc98974), anti-sucrase-isomaltase (SI) (sc27603), anti-SLC6A20 (sc134762), antiSLC6A19 (sc160812), anti-SLC36A1 (sc368553) antibody and donkey anti-goat IgG-HRP (sc-2020) were from Santa Cruz Biotechnology (Dallas, TX). Anti-mouse and anti-rabbit HRP conjugate and Amersham ECL Western Blotting Detection Reagents (RPN2106) were from GE Healthcare Life Sciences.

\section{Animals}

The Washington University School of Medicine Animal Studies Committee reviewed and approved all animal experimentation. Tis $7^{t g}$ mice were generated as per [11] on an FVB/N background. WT FVB/N littermates were used as controls for all $t i{ }^{t} 7^{t g}$ experiments. All mice were bred and housed together in the same room of the Washington University School of Medicine mouse facility. The mice were fed a standard rodent chow diet (Picolab 20, Ralston Purina) containing by weight $20.0 \%$ protein, $5.6 \%$ fat, $4.7 \%$ fiber, $52.9 \%$ carbohydrate, $6.1 \%$ minerals, $0.7 \%$ vitamins and $10 \%$ water, and were kept on a strict $12 \mathrm{hr}: 12 \mathrm{hr}$ light dark cycle. Protein, fat and carbohydrate accounted for $24.7 \%, 13.2 \%$ and $62.1 \%$ of calories, respectively.

\section{Intestinal resection surgery}

The protocols for intestinal resection surgery and for the provision of a liquid high fat diet ( $42 \% \mathrm{kcals}$ from fat, Modified, High Fat AIN-93M purified liquid diet 710147, Dyets Inc, Bethlehem PA) for 3 weeks post-op were as described [7]. Briefly, two days prior to surgery mice were acclimated to a liquid control diet nutritionally equivalent to standard rodent chow (described below). On the day of surgery mice were anesthetized with ketamine $(87 \mathrm{mg} / \mathrm{kg})$ xylazine HCL $(13 \mathrm{mg} / \mathrm{kg})$ and isoflurane inhalation. A $50 \%$ small bowel resection was performed starting $3 \mathrm{~cm}$ from the ligament of Treitz and ending $8 \mathrm{~cm}$ from the ileocecal junction [20]. A primary end-to-end anastomosis was made between the remaining jejunum and ileum and the abdominal cavity was closed in two layers. For control sham surgeries a single incision was made $9 \mathrm{~cm}$ from the ileocecal junction, and the intestine was re-sutured at this site and the abdominal cavity closed as above. Mice received $0.2 \mathrm{mg}$ gentamicin in $0.5 \mathrm{ml}$ saline, $0.03 \mathrm{mg} / \mathrm{kg}$ buprenorphine I.P. for analgesia, and $2.5 \mathrm{cc} 0.9 \%$ sodium chloride I.P. for fluid resuscitation. Mice recovered in an Air Shields isolette incubator at $31^{\circ} \mathrm{C}$ overnight, and were sacrificed on day 21 post-resection. Remnant duodenum-jejunal, ileal and anastomotic segments were harvested and frozen in liquid nitrogen or fixed in formalin. Mice that had poor p.o. intake, excessive weight loss, or were otherwise distressed based on daily monitoring were sacrificed and excluded from further analyses.

High fat diet feeding post surgery

The high fat liquid diet was prepared by liquefying $225.0 \mathrm{~g}$ of diet powder in $1 \mathrm{~L}$ water in a food processor for $30 \mathrm{sec}$, containing $38.7 \mathrm{~g} / \mathrm{L}$ protein (casein, $100 \mathrm{mesh}$ ), $0.5 \mathrm{~g} / \mathrm{L}$ L-cystine, $35.6 \mathrm{~g} / \mathrm{L}$ milk fat, $11.1 \mathrm{~g} / \mathrm{L}$ soybean oil, $27.7 \mathrm{~g} / \mathrm{L}$ sucrose, $81.5 \mathrm{~g} / \mathrm{L}$ maltose dextrin, $3 \mathrm{~g} / \mathrm{L}$ xanthan gum, $13.8 \mathrm{~g} / \mathrm{L}$ cellulose (fiber), $9.7 \mathrm{~g} / \mathrm{L}$ minerals and $2.77 \mathrm{~g} / \mathrm{L}$ vitamins. Protein, fat and carbohydrate accounted for $140.5,420.3$ and $420.5 \mathrm{kcal}$ per liter of liquid diet, respectively. Mice were fed the high fat diet for 21 days postop. Calorie intake and weights were monitored q1- 2days.

In vitro intestinal glucose, proline and leucine uptake measurements

In vitro intestinal glucose (glc), proline (pro) and leucine (leu) uptake were measured using a modified everted sleeve technique $[15,21]$. Intestines from 3-month old tis $7^{\text {tg }}$ mice and WT littermates were used for glucose and proline uptake experiments ( $\mathrm{n}=5 \mathrm{tis} 7^{\mathrm{tg}}, \mathrm{n}=6 \mathrm{WT}$ ), and for leucine uptake and cell-surface biotinylation experiments $\left(\mathrm{n}=6 \mathrm{tis} 7^{\mathrm{tg}}, \mathrm{n}=6 \mathrm{WT}\right.$ ). To minimize the effect of diurnal variation in expression and function of hexose transporters, one mouse per day was sacrificed between 9:30 AM to 10:00 AM. The small intestine was rapidly removed, placed on a cold chop board and divided into three segments: the proximal $10 \mathrm{~cm}$, the middle $16-20 \mathrm{~cm}$ and the distal $9 \mathrm{~cm}$, designated as duodenum, jejunum and ileum. The proximal $4 \mathrm{~cm}$ of duodenum and the distal $3 \mathrm{~cm}$ of ileum were snap frozen in liquid nitrogen for RNA isolation; the middle $4 \mathrm{~cm}$ of duodenum and ileum were cut in half as duplicates for glucose or leucine uptake determinations; the middle $4 \mathrm{~cm}$ of jejunum was cut in half for proline or leucine uptake and the adjacent $4 \mathrm{~cm}$ was saved for cell-surface biotinylation. After the luminal contents were gently removed, a 2-cm intestinal segment was tied with 5-0 nylon suture (Surgical Specialties Corp., Reading, PA) at one end, which served as an anchor on the flat end of a stainless steel round rod $(1.57 \times 300 \mathrm{~mm})$. The rod was advanced into the intestinal lumen and the segment everted on the rod. A $1.0 \mathrm{~cm}$ everted sleeve was 
secured on the rod with two 5-0 suture ties and extra tissue removed from both edges. The sleeves were maintained in chilled $\left(4^{\circ} \mathrm{C}\right)$ mammalian Ringers solution $(128 \mathrm{mM} \mathrm{NaCl}, 4.7 \mathrm{mM} \mathrm{KCl}, 2.5 \mathrm{mM} \mathrm{CaCl}, 1.2 \mathrm{mM}$ $\mathrm{KH}_{2} \mathrm{PO}_{4}, 1.2 \mathrm{mM} \mathrm{MgSO}_{4}, 20 \mathrm{mM} \mathrm{NaHCO}_{3}, \mathrm{pH}$ 7.3-7.4) bubbled with 95\% $\mathrm{O}_{2} / 5 \% \mathrm{CO}_{2}$ until ready for the uptake measurement. About $75 \mathrm{~min}$ after sacrifice, everted sleeves were inserted in 3-hole cork stoppers in pairs and sequentially placed in a flat bottom round tube $(25 \times 150 \mathrm{~mm})$ in a $38^{\circ} \mathrm{C}$ bath and pre-incubated in 8 $\mathrm{ml}$ of mammalian Ringers solution bubbled with $95 \% \mathrm{O}_{2} / 5 \% \mathrm{CO}_{2}$ for $5 \mathrm{~min}$. Each pair of everted sleeves was then transferred to another flat bottom round tube in a $38^{\circ} \mathrm{C}$ bath and incubated in $8 \mathrm{ml}$ of mammalian Ringers solution with iso-osmotic replacement of $\mathrm{NaCl}$ using $20 \mathrm{mM}$ non-radiolabeled D-Glc, L-Pro or L-Leu and containing $1 \mu \mathrm{Ci}$ of each probe $\mathrm{D}-\left[{ }^{14} \mathrm{C}(\mathrm{U})\right]$ glucose (D-glc), L- $\left[{ }^{14} \mathrm{C}(\mathrm{U})\right]$ proline (L-pro), L- $\left[{ }^{14} \mathrm{C}(\mathrm{U})\right]$ leucine (L-leu) and and $2 \mu \mathrm{Ci}$ of marker (radiolabeled markers L- $\left[1-{ }^{3} \mathrm{H}\right]$ glucose and $\left[1,2-{ }^{3} \mathrm{H}\right] \mathrm{PEG} 4000$ for proline and leucine uptake experiments). The solution was stirred at 1,200 rpm to mix the unstirred layer. After 1 min incubation, the tissues were removed, rinsed quickly in $25 \mathrm{ml}$ of chilled mammalian Ringers solution stirred at 1,200 rpm for $20 \mathrm{~s}$, and placed in glass scintillation vials. Tissue solubilizer was added to the vials and incubated at $37^{\circ} \mathrm{C}$ overnight. After complete solubilization, $5 \mathrm{ml}$ of Ultima Gold cocktail was added and radioactivity measured in a Beckman LS 3801 scintillation counter. The probe uptake rate $J$ is defined as $J=$ $(P-R \cdot M) /(H \cdot t \cdot m)$, where $P$ and $M$ represent the DPM of the probe and marker in the tissue, respectively, $R$ is the ratio of the probe radioactivity over the marker radioactivity in the incubation solution, $H$ is the ratio of the probe radioactivity to the total amount of radiolabeled and non-radiolabeled probe in nmol, $t$ is the incubation time and $m$ is the length of intestine. $\left[1,2-{ }^{3} \mathrm{H}\right]$ PEG 4000 was used as a marker in the pro and leu uptake experiments to measure adherent fluid and $\mathrm{L}-\left[1-{ }^{3} \mathrm{H}\right]$ glucose was used in the glc uptake experiment to measure adherent glucose and passive uptake. Thus, the resulting rates measured were total uptake rates for pro and leu, and active transporter-mediated uptake rate for glc, respectively.

Intestinal gene expression analysis by $q R T-P C R$

Total RNA from duodenum and ileum was extracted by TRIzol and treated with DNase I using the DNA-free kit. First strand cDNA was synthesized from $1.5 \mu \mathrm{g}$ of total RNA using Super-Script II reverse transcriptase with random hexamer primers. Real time PCR analysis was performed on an StepOnePlus Real-Time PCR system (Applied Biosystems, Foster City, CA) using 2x Sybr Green Master Mix. Primers used in quantitative RT-PCR are as follows: Slc38a2: forward, 5'- GGC TAT GTC AAG CTA CCT CTTC-3'; and reverse, 5'- GTC ACC GTT CAG ATA CCA CAA-3'; Slc6a196A19: forward, 5'- TGT CAA CAC GAA CAT CCT GAC CCT-3'; and reverse, 5' - TTA GTG GCA TTG CAC CAC TGT TGG-3'; SLC6A14: forward, 5' - CCT CTG GCA AGG TGG TAT ATTT-3'; and reverse, 5'- TCC AAA GTT GCA CCT CGT ATTA-3'; Slc6a20a: forward, 5'- GAT GTA CGG CGG AGG GAG TTTC-3'; and reverse, 5'- AGA CCA CAA CAC TGG CAA CAC; SLC36A1: forward, 5'- CAT CGT GGA CTT CTT CCT CATC-3'; reverse, 5'- CTG CCT CTA TCA CCT GCT TAAA-3'; Ace2: forward, 5'- CCC AAA GAG CAG TGG ATGAA-3'; reverse, 5' - GAG ATG CAG GGT CAC AGT ATG-3'; Sgk1K1: forward, 5'- GGC TAT CTG CAC TCC CTA AAC-3'; reverse, 5' - AAA GTC AGT GAG GAC GAT GTG-3'; GAPDH, 5'- TGT GTC CGT CGT GGA TCT GA-3'; reverse, 5'- CCT GCT TCA CCA CCT TCT TGA-3'. The relative mRNA level was defined as $2^{-\Delta C \mathrm{~T}}$, where $\Delta \mathrm{C}_{\mathrm{T}}=\mathrm{C}_{\mathrm{T}}$ gene of interest $-\mathrm{C}_{\mathrm{T}}$ internal control [22], and the internal control was GAPDH.

\section{Intestinal apical cell-surface biotinylation}

Intestinal apical cell surface biotinylation was carried out using Pierce Cell Surface Protein Isolation Kit per manufacturer's instructions modified as per [23-25]. Briefly, a 4-cm jejunal segment from the leu uptake experiment was flushed with cold PBS-CM (PBS with $0.1 \mathrm{mM} \mathrm{CaCl}, 1.0 \mathrm{mM} \mathrm{MgCl}_{2}, \mathrm{pH} 7.2$ ). Both ends of the segment were closed with 5-0 nylon sutures, placed on a cold chop board, and 0.3 mL of fresh $1.0 \mathrm{mg} / \mathrm{mL}$ sulfo-NHS-SS-biotin in ice-cold PBS-CM was injected into the lumen and incubated at $4^{\circ} \mathrm{C}$ for $30 \mathrm{~min}$. Both ends of the loops were removed and the lumen was flushed twice with $2.5 \mathrm{~mL}$ of ice-cold PBS /100 mM glycine buffer to quench the free biotin, and then twice with $2.5 \mathrm{~mL}$ of ice-cold TBS. The loop was cut longitudinally along the opposite side of the mesentery to expose the luminal surface. Mucosa was scraped with a microscope slide and suspended in $1.0 \mathrm{~mL}$ of cold TGH lysis buffer containing 1\% (v/v) Triton X-100, 10\% (v/v) Glycerol, 25 mM HEPES (pH 7.4) and 5 mM EDTA. $10 \mu \mathrm{L}$ of the 100x Halt Protease and Phosphatase Inhibitor Cocktail was added and the mucosa was homogenized with a Polytron PT 10/35 tissue homogenizer (Brinkmann Instruments, Westbury, NY) at 23,000 rpm for $7 \mathrm{sec}$, and then incubated on ice for $30 \mathrm{~min}$ with occasional brief vortexing. The mucosal lysate was centrifuged at 10,000x g for 2 $\min$ at $4{ }^{\circ} \mathrm{C}$. The supernatant and pellet were stored at $-20^{\circ} \mathrm{C}$ without separation. The protein concentration was determined by the CB-X protein assay (G-Biosciences, St. Louis, MO). NeutrAvidin Agarose slurry (500 KARGER 


\section{Cellular Physiology Cell Physiol Biochem 2016;38:1532-1543 \begin{tabular}{l|l} 
and Biochemistry Published online: April 07, 2016 & $\begin{array}{l}\text { D) 2016 The Author(s). Published by S. Karger AG, Basel } \\
\text { www.karger.com/cpb }\end{array}$ \\
\hline
\end{tabular} \\ Lu et al.: Reduced Proline Absorption in Tis7 Transgenic Mice}

$\mu \mathrm{L}$ ) in a column was washed with $3 \mathrm{x} 500 \mu \mathrm{L}$ of Wash Buffer. The clarified cell lysate containing $1.0 \mathrm{mg}$ of total soluble proteins was added to the column, which was placed on a rotary mixer and incubated at room temperature (RT) for $60 \mathrm{~min}$. The column was then centrifuged for $1 \mathrm{~min}$ at $1000 \mathrm{x} g$ and flow-through discarded. The column was washed four times with $500 \mu \mathrm{L}$ of Wash Buffer containing $5 \mu \mathrm{L}$ of $100 \mathrm{x}$ inhibitor cocktail, and then $400 \mu \mathrm{L}$ of the Sample Buffer (2.5 parts of 4x NuPAGE LDS sample buffer, 1 part of $0.5 \mathrm{M}$ DDT and 6.5 parts of water) was added to release the bound biotinylated proteins. The column was then placed on a rotary mixer and incubated at RT for $60 \mathrm{~min}$. Column was centrifuged for $2 \mathrm{~min}$ at $1000 \times g$ and the eluate stored at $-20^{\circ} \mathrm{C}$ for immunoblotting.

Intestinal epithelial protein expression analysis by immunoblot

Intestinal epithelial protein expression by immunoblot was carried out using the XCell SureLock MiniCell for electrophoresis and iBlot 7-minute blotting system for protein transfer (Life Technologies, Carlsbad, CA). Samples were prepared according to manufacturer's instruction and $15 \mu \mathrm{g}$ of total soluble proteins or $6.5 \mu \mathrm{g}$ of cell-surface biotinylated proteins were loaded onto a NuPAGE Novex 10\% Bis-Tris Gel (1.0 mm, 10 Well). A sample containing $15 \mu \mathrm{g}$ of total soluble proteins from a full-thickness jejunum segment of a C57BL/6 WT mouse was loaded on each gel as an inter-gel normalization standard. Protein ladders were transferred to a nitrocellulose membrane. After blocking with $5 \%$ non-fat dry milk in TBS/0.1\% Tween 20 at RT $1 \mathrm{~h}$, the blot was incubated at $4^{\circ} \mathrm{C}$ overnight with the primary antibody, followed by incubation with a horseradish-conjugated secondary antibody at RT for $1 \mathrm{~h}$, and visualized by Amersham ECL Western Blotting Detection Reagents on autoradiography film (Molecular Technologies, St Louis, M0). Anti-pThr256SGK, anti- $\beta$-actin, anti-SGLT1, anti-SI, anti-SLC6A20, anti-SLC6A19 antibodies were sequentially employed in western blotting of total soluble proteins, whereas anti-SGLT1, anti-SI, anti-SLC6A20, anti-SLC6A19, anti-SLC36A1 and anti- $\beta$-actin were sequentially employed in immunoblotting of cell-surface biotinylated proteins. All primary antibodies were used in 1:200 dilutions in TBS/0.1\% Tween 20/5\% non-fat dry milk. All secondary antibodies were used in 1:10,000 dilutions in TBS/0.1\% Tween 20/5\% non-fat dry milk except for anti-SLC36A1 antibody detection, which was diluted 1:2000. The mild stripping procedure used at the end of each round of immunoblotting entailed incubation twice for $10 \mathrm{~min}$ in stripping buffer (106.6 $\mathrm{mM}$ glycine, $0.1 \%$ SDS, $1 \%$ Tween $20, \mathrm{pH} 2.2$ ), followed by incubation twice in PBS and then by washing twice for $5 \mathrm{~min}$ in TBS/0.1\% Tween 20. Protein bands on the immunoblot were quantified using ImageJ software (http://rsb.info.nih.gov/ij/index.html). The measured density of the experimental sample was normalized to the standard sample, and then normalized to the loading controls $\beta$-actin and SGLT1 for the analyses of total soluble proteins and cell-surface biotinylated proteins.

\section{Statistical analysis}

Unpaired Student's t-tests were performed for analysis of data from tis $7^{\text {tg }}$ vs. WT littermate mice; $a p$ value $\leq 0.05$ was considered statistically significant.

\section{Results}

Glucose uptake is unaltered by enterocytic tis 7 overexpression

Active transporter-mediated glucose uptake rates in everted sleeves were similar to previously reported (normal) rates [15] and there was no difference in average active glucose uptake rates in WT compared to tis $7^{\text {tg }}$ transgenic duodenum $\left(85 \mathrm{nmol} \mathrm{min} \mathrm{mm}^{-1} \mathrm{cs}^{-1}\right.$ $106 \mathrm{nmol} \mathrm{min}^{-1} \mathrm{~cm}^{-1}$ respectively ( $\mathrm{p}=\mathrm{NS}$, Fig. 1A); Glucose uptake rates were also unchanged in tis $^{7^{\text {tg }}}$ compared to WT ileum (Fig. 1A). As expected, glucose uptake rates were significantly lower in both WT and tis ${ }^{\text {tg }}$ ileum compared to WT and tis $^{\text {tg }}$ duodenum respectively, consistent with the known regional patterns of SGLT1 expression [21]. Thus enterocytic tis7 overexpression did not affect glucose uptake.

\section{Reduced small intestinal proline uptake in tis $7^{\text {tg }}$ jejunum}

Because the neutral amino acid cotransporter Slc6a19 null mouse has a similar phenotype to the tis $7^{\text {tg }}$ mouse, with significantly lower body weight compared to WT littermates when fed a chow diet [18], we examined the uptake of neutral amino acids including L-proline and leucine [15]. As shown in Fig. 1B, the average proline uptake rate 

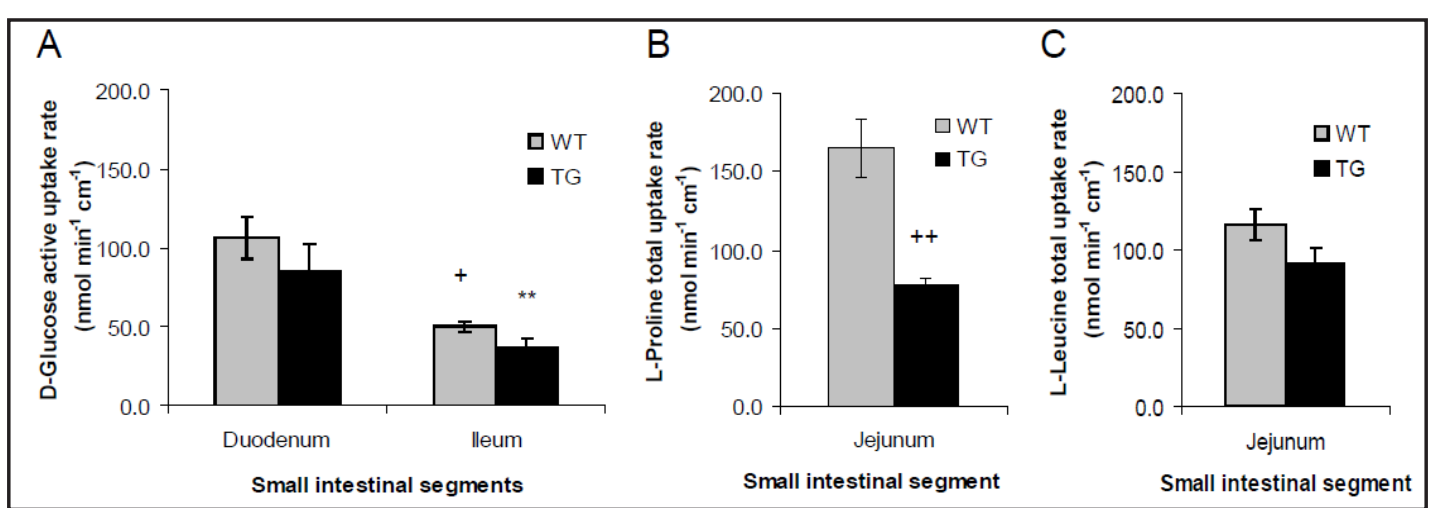

Fig. 1. Reduced proline transport in Tis $7^{t g}$ vs. WT small intestine. Uptake rates of D-glucose (A), proline (B) and leucine $(\mathrm{C})$ were measured in vitro by the everted sleeve technique. (A) Glucose uptake rates are higher in duodenum compared to ileum but there is no significant difference comparing tis $^{\text {tg }}$ to WT. WT duodenum vs. WT ileum ; + p $\leq 0.05$; Tis $7^{\text {tg }}$ duodenum vs. tis $^{\text {tg }}$ ileum ${ }^{* *} \mathrm{p} \leq 0.05$. (B) Proline uptake is reduced in tis $7^{\text {tg }}$ vs WT jejunum; $++p \leq 0.05$. (C). Leucine uptake is unchanged in $t i s 7^{t g} v s$ WT jejunum. Error bars represent the SEM.

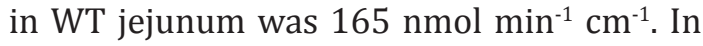
contrast, the average proline uptake rate in tis $7^{\text {tg }}$ jejunum was significantly reduced to 77 nmol $\min ^{-1} \mathrm{~cm}^{-1}(\mathrm{p}<0.01)$.

To determine whether the reduction in amino acid uptake was unique to proline or if transport of other neutral amino acids was affected by tis7 overexpression, we measured leucine uptake rates. Average leucine uptake in WT jejunum was $116 \mathrm{nmol} \mathrm{min}{ }^{-1} \mathrm{~cm}^{-1}$ (Fig. 1C) and the average tis $7^{\text {tg }}$ jejunal leucine

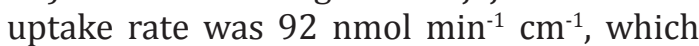
was not significantly different from WT. To determine whether regional variation in leucine uptake along the horizontal axis of the intestine might mask differences between WT and TG, we measured uptake in

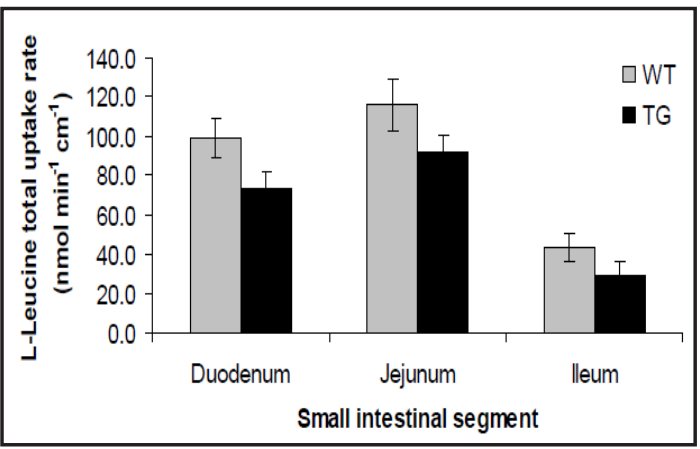

Fig. 2. Leucine uptake is unchanged in tis $7^{\text {tg }}$ vs. WT duodenum, jejunum and ileum. Leucine uptake was measured as per Methods. Leucine uptake rates in duodenum and jejunum are higher than in ileum but there were no significant differences comparing WT vs. tis ${ }^{\text {tg }}$ leucine uptake.

the duodenum and ileum (Fig. 2). Leucine uptake rates were highest in WT jejunum (116

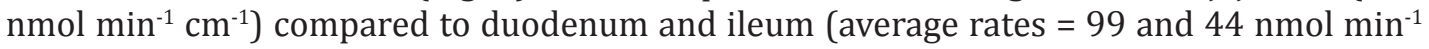
$\mathrm{cm}^{-1}$ respectively), but there were no significant differences comparing WT vs. tis $7^{\text {tg }}$ leucine uptake in duodenum or ileum.

\section{Altered expression of amino acid transporters in tis $7^{\text {tg }}$ and WT small intestine}

To begin to elucidate the molecular mechanisms regulating the observed reduction in proline uptake, we analyzed amino acid transporter expression in the $t^{i s} 7^{\text {tg }}$ and WT duodenum and ileum by qRT-PCR. The amino acid transporters that transport neutral amino acids including proline in the gut are SLC38A2 (SNAT2), SLC6A19 (B ${ }^{0}$ AT1), SLC6A14, and SLC36A1 (PAT1) [17]. SLC6A20 (SIT1) is specific for proline/imino acids.

Of the five transporters, Slc6a20a mRNA was the most abundantly expressed among all transporters in the jejunum. Slc6a14 mRNA expression was lowest along the entire length of the small bowel (Fig. 3A-C). Slc6a20, Slc38a2 and Slc36a1 (Pat1) were most abundantly expressed in jejunum compared to duodenum and ileum, whereas Slc6a14 levels were highest in ileum. Slc6a19 had similar expression levels in jejunum and ileum.

Comparing Tis $^{\text {tg }}{ }^{\text {to }}$ WT there was a small (1.3-fold) but significant increase in duodenal Slc6a19 expression (Fig. 3A), and a significant increase in duodenal (2.3-fold) and ileal (1.2fold) Slc36a1 expression (Fig. 3A and 3C, respectively).

\section{KARGER}


Reduced SGK1 mRNA expression in tis $7^{\text {tg }}$ ileum

Although proline uptake was reduced in tis $7^{\text {tg }}$ vs. WT intestine, transporter expression levels were either unchanged or showed a small but significant increase in $t i s 7^{\text {tg }}$ vs WT intestine (Fig. 3). Thus we next sought to examine the expression of genes that regulate transporter activity and/or its cell surface expression, which in turn might be regulated by tis 7 overexpression, via its function as a transcriptional co-regulator. Angiotensin-converting enzyme 2 (ACE2) is a cell-surface expression partner of SLC6A19 [26]. We observed regional differences in Ace 2 expression levels along the length of the small bowel, with a significant increase in ileal compared to duodenal Ace2 expression in both WT and $t i s 7^{\text {tg }}$ mice (3.2-fold and 2.3fold, respectively, ${ }^{*} \mathrm{p}<0.0001$ for both, Fig. 4A). However, intestinal tis7 overexpression did not affect Ace2 mRNA levels as there was no significant difference in Ace2 expression in WT vs Tis $7^{\text {tg }}$ duodenum or ileum (Fig. 4A).

SGK1, 2 and 3 play important roles in regulating amino acid transporter activity [27]. PI3

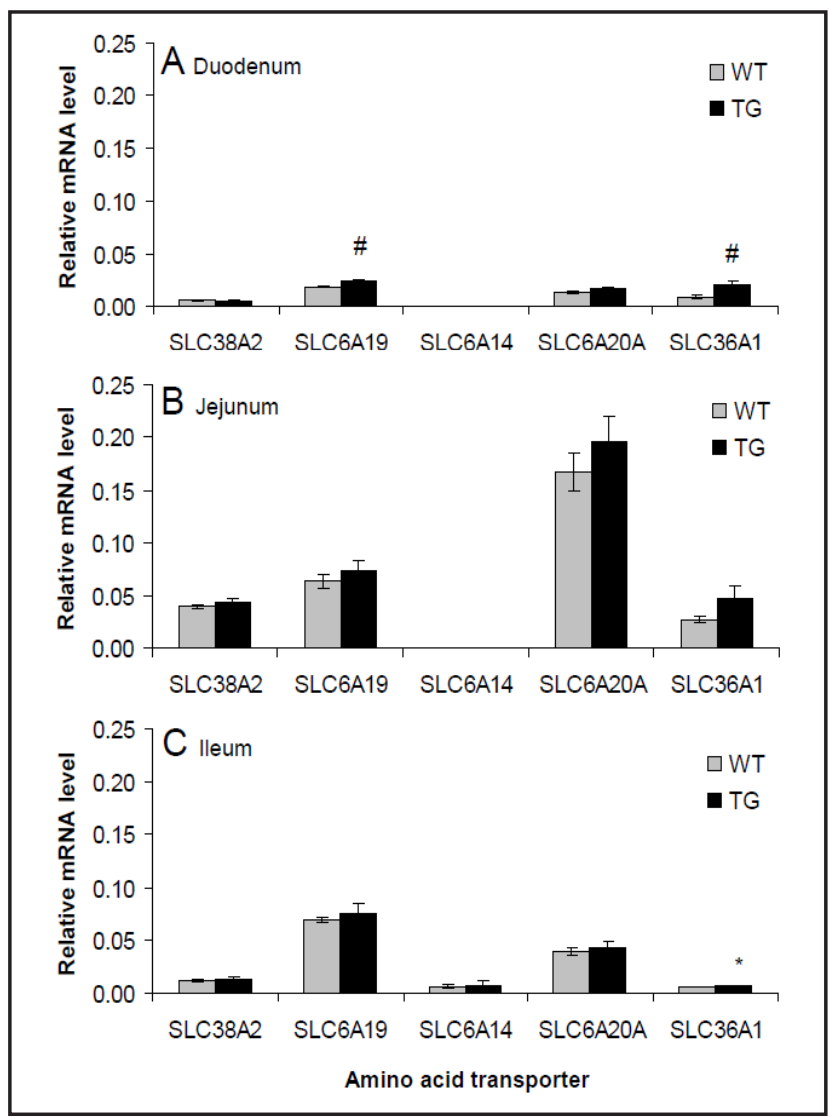

Fig. 3. Amino acid transporter mRNA expression in WT and tis $7^{t g}$ small intestine. Relative mRNA expression in (A) duodenum (B) jejunum, and (C) ileum was measured by qRT-PCR. (A). WT vs tis $7^{t g}$ duodenum, \# $\mathrm{p} \leq 0.05$. (C). WT vs tis $7^{\text {tg }}$ ileum, $* \mathrm{p} \leq 0.05$. Error bars represent the SEM.

kinase activates SGKs which then stimulate intestinal glucose and amino acid transporters; global inhibition of PI3 kinase inhibits amino acid and glucose transport via inhibition of SGK activation. SGK1 has also been shown to enhance cell-surface expression of SLC6A19 in Xenopus oocytes [25]. Since SGK1 has five isoforms (SGK1a-e) [28-30], a primer pair from the conserved region of these isoforms was chosen so that the total mRNA level was measured by qRT-PCR.

We observed significant regional differences in $S g k 1$ expression, with increased $S g k 1$ expression in ileum compared to duodenum and in jejunum compared to duodenum in both WT and tis $7^{\text {tg }}$ mice (3.0-fold higher in WT ileum vs. duodenum ( $\left.\mathrm{p}<0.0001\right), 2.3$-fold higher in tis $7^{t g}$ ileum vs. duodenum ( $\left.<<0.008\right), 2.6$ fold higher in WT jejunum vs. duodenum ( $\mathrm{p}$ $<0.002$ ) and 1.9 fold higher in tis $7^{\text {tg }}$ jejunum vs. duodenum ( $<<0.019$; Fig. 4B)). We also observed significantly decreased $S g k 1$ mRNA levels in $t i s 7^{\text {tg }}$ compared to WT jejunum (2.1fold, $\mathrm{p}<0.013$ ) and ileum (2.1-fold, $p<0.002$, Fig. 4B). Sgk2 mRNA levels were also lower in tis $7^{\text {tg }}$ vs. WT duodenum (1.3-fold, p<0.005) but not in other intestinal segments. Sgk3 mRNA levels were unchanged.

\section{Reduced activated SGK1 expression (pSGK1) in tis $7^{\text {tg }}$ jejunum}

Proline transporter cell surface expression is regulated by activated SGK1, thus we hypothesized that decreased activated SGK1 expression might in turn reduce transporter cell surface expression. Therefore we examined the expression of activated SGK1 (pSGK1) which is phosphorylated at residues Thr349 and Ser515, by immunoblot analysis (Fig. 5A).

\section{KARGER}


All five phosphorylated SGK isoforms1a-e and phosphorylated SGK2 were detected on the immunoblot, including pSGK1a (59.7 $\mathrm{kDa}$ ), pSGK1b (46.1 kDa), pSGK1c (47.7 kDa), pSGK1d (50.7 kDa) and pSGK1e (49.1 kDa). Quantification of pSGK1 expression was based on the total phosphorylated protein rather than individual isoforms. Activated SGK1 expression was 2.7 fold higher in the WT mouse compared to Tis $7^{\text {tg }}$ mouse (Fig. 5B). pSGK2 expression in the tis $7^{\text {tg }}$ intestine also trended lower than WT $(\mathrm{p}=0.1)$.

Reduced intestinal apical membrane expression of the proline-specific transporter SLC6A20 in tis $7^{\text {tg }}$ mice

To determine whether decreased pSGK1 was associated with decreased amino acid transporter cell-surface expression [25], jejunal total cellular (Fig. 6A) as well as api cal membrane expression (Fig. 6B) of the neutral amino acid transporter SLC6A19 and the proline-specific transporters SLC6A20 and SLC36A1 were examined by immunoblot. Apical membrane expression was measured by surface biotinylation. The glucose transporter SGLT1 and the intestinal absorptive cell surface membrane protein sucroseisomaltase (SI) were included as controls.

Densitometric analysis revealed that the total cellular expression levels of these five

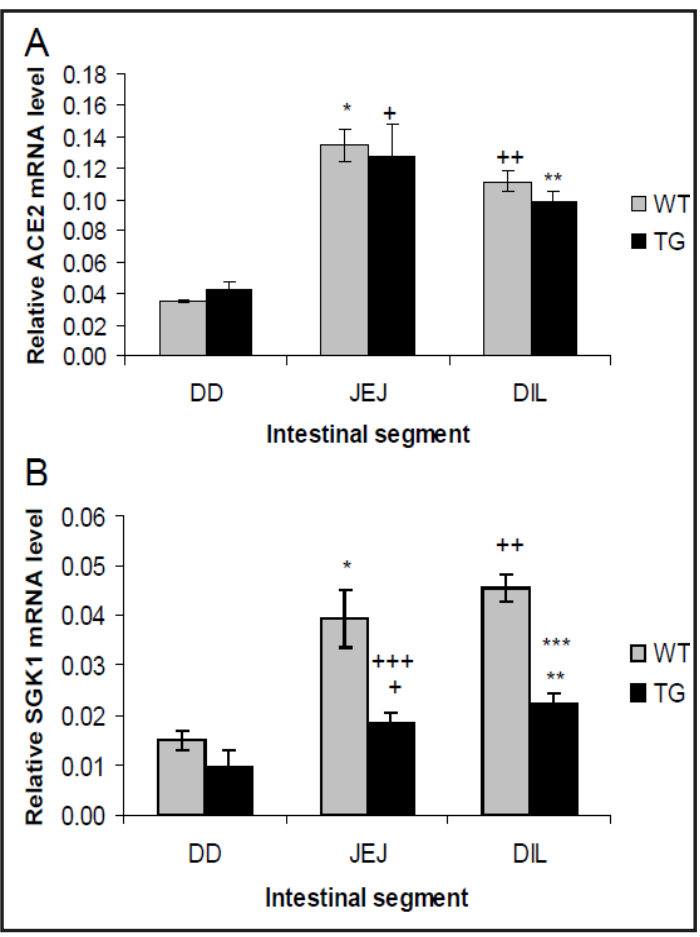

Fig. 4. $S G K 1$ but not ACE2 mRNA expression is reduced in tis $^{\text {tg }}$ vs. WT jejunum (JEJ) and ileum (DIL). Relative mRNA expression of the transporter co-regulators ACE2 (A) and SGK1 (B) was measured by qRT-PCR. (A). WT duodenum (DD) vs. WT JEJ, * $\mathrm{p} \leq$ 0.05; tis $7^{t g}$ DD vs. tis $7^{t g} \mathrm{JEJ},+\mathrm{p} \leq 0.05$; WT DD vs WT DIL, $++\mathrm{p} \leq 0.05$; tis $7^{\text {tg }}$ DD vs. tis $7^{\text {tg }}$ DIL, ${ }^{* *} \mathrm{p} \leq 0.05$. B. WT DD vs. WT JEJ, * ${ }^{*} \leq 0.05$; tis $7^{\text {tg }}$ DD vs. tis $7^{\text {tg }} \mathrm{JEJ},+$ $\mathrm{p} \leq 0.05$; WT JEJ vs. Tis $7^{t g} \mathrm{JEJ},+++\mathrm{p} \leq 0.05$. WT DIL vs. Tis $7^{\text {tg }}$ DIL, ${ }^{* * *} \mathrm{p} \leq 0.05$.

proteins were not different in WT and tis $7^{\text {tg }}$ jejunum (Fig. 6C). Evaluation of apical membrane expression by cell surface biotinylation revealed that all 5 proteins were readily detected in the apical membrane-bound fraction. To control for variability in cell-surface biotinylation, SGLT1 was used as a loading control. We observed a small (13\%) but significant decrease in Tis $7^{\text {tg }}$ compared to WT jejunal apical membrane expression of the Pro-specific transporter SLC6A20 (Fig. 6D, p < 0.048). Cell surface expression of SLC6A19 and SLC36A1 were unchanged.

Body weight gain is unchanged in high fat fed tis $7^{\text {tg }}$ mice post resection

Weight gain and maintenance of adequate oral nutrition after massive small bowel resection is a major clinical problem for patients with short bowel syndrome. Tis $7^{\text {tg }}$ mice were previously shown to have accelerated triglyceride absorption and exhibit a phenotype that mimics some of the metabolic changes found in parenteral nutrition dependent patients with short bowel syndrome [11]. We therefore employed a mouse model of short bowel syndrome, to determine whether intestinal tis7 overexpression could increase weight gain post resection. We performed $50 \%$ small bowel resections and fed a high saturated fat diet to $t i s 7^{t g}$ and WT mice for 21 days post resection, Daily weights were measured. We observed that body weight recovery was the same in $t i s 7^{\text {tg }}$ and WT mice throughout the entire 21 day post op period (Fig. 7). 


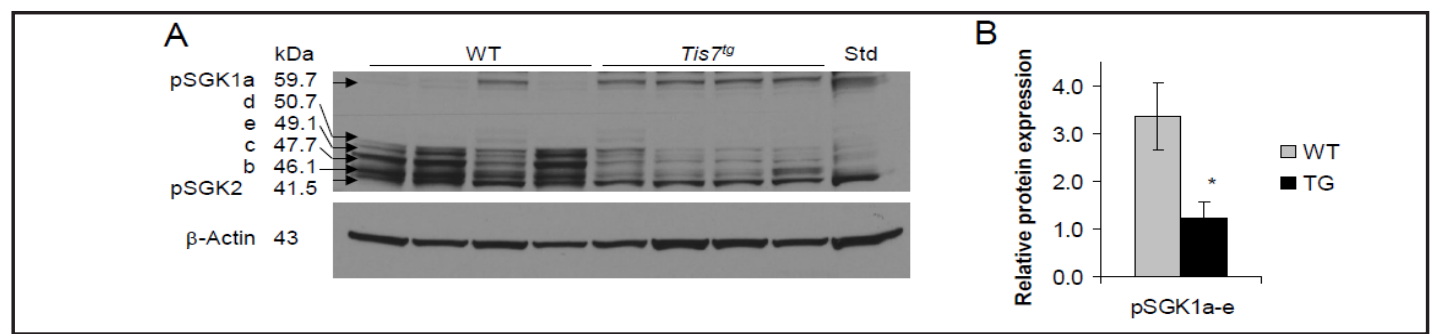

Fig. 5. Reduced expression of phosphorylated SGK1 (pSGK1) in $t i s 7^{t g}$ vs. WT jejunum. (A) Immunoblot showing the expression of activated (phosphorylated) SGK1 isoforms a-e (pSGK1a-e) and pSGK2 in jejunal mucosa. The first 4 lanes from left are WT, the next 4 lanes are $t i s 7^{t g}$, and the right lane is the molecular weight standard. $\beta$-actin was measured as a loading control. (B) Protein expression was quantified as the adjusted density of the protein band or the sum of protein bands in case of pSGK1a-e. * $\mathrm{p} \leq 0.05$ WT vs. tis $7^{\text {tg }}$ JEJ; error bars represent the SEM. WT, wild type, TG, transgenic.

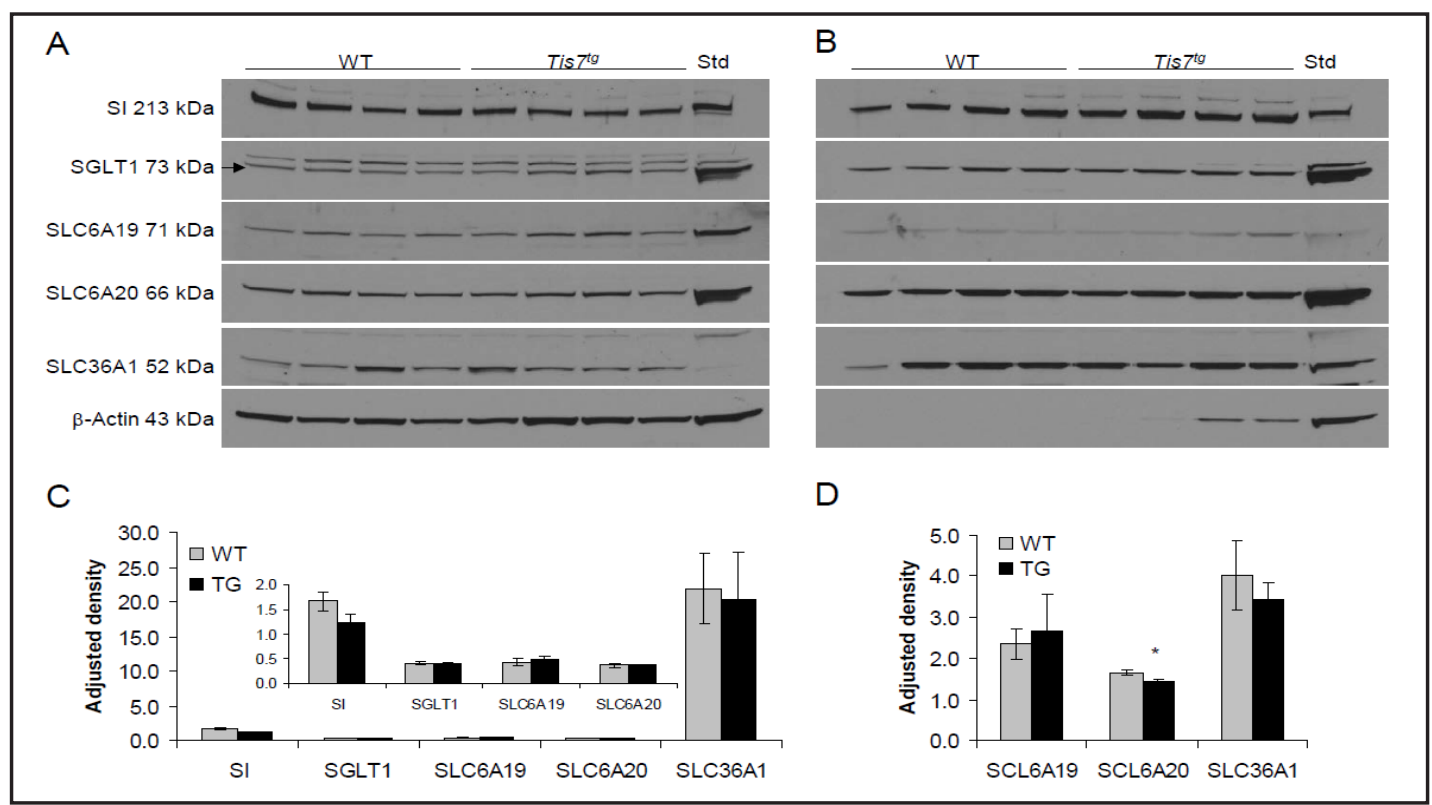

Fig. 6. Reduced intestinal apical membrane expression of the proline-specific transporter SLC6A20 in tis $7^{\text {tg }}$ mice. (A) Immunoblot analysis of total cellular expression of the intestinal brush border protein sucrase-isomaltase (SI), and transporters for Glc (SGLT1), Pro (SLC6A20 and SLC36A1) and Leu (SLC6A19) in the supernatant of jejunum mucosa. (B) Expression in the apical membrane-bound fraction isolated through cell-surface biotinylation and analyzed by immunoblot. $\beta$-actin and SGLT1 served as the respective loading controls. Expression was quantified as the normalized densities of protein bands, as in (C) and (D), respectively. The inserted chart in (C) is a scale-adjusted quantification of SI, SGLT1, SLC6A19 and SLC6A20 protein expression. ${ }^{*} \mathrm{p} \leq 0.05$ WT vs. Tis $7^{\text {tg }}$ jejunum ; error bars represent the SEM.

Fig. 7. Body weight recovery is unchanged in high fat diet fed $t i s 7^{t g}$ vs. WT mice after $50 \%$ small bowel resection. Mice had 50\% small bowel resection and were fed a high saturated fat "Western" diet for 21 days post resection. Body weight was measured daily.

\section{Discussion}

We have previously observed that chowfed tis $7^{\text {tg }}$ mice have decreased body weight with a relative increase in adiposity (due

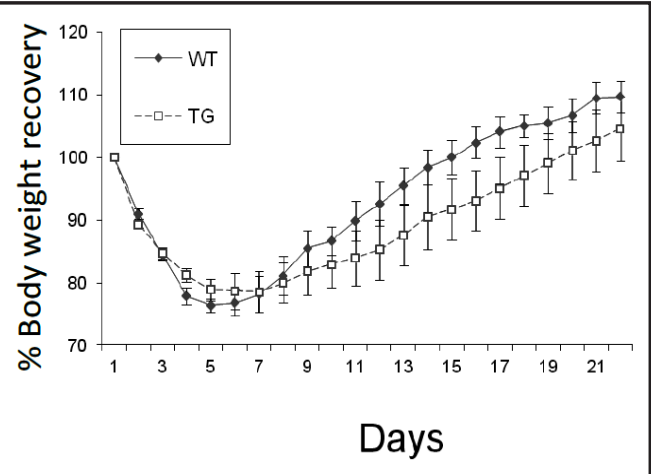
KARGER 
to enhanced triglyceride absorption) yet a reduction in lean body mass compared to WT littermates [11]. Herein we have shown that tis7 overexpression in intestinal enterocytes results in reduced proline but not reduced leucine uptake, decreased expression of activated SGK1 and decreased cell surface expression of the proline/ imino acid transporter SLC6A20. Reduced intestinal proline transport may in part explain the reduction in lean body mass in tis $7^{\text {tg }}$ mice, as well as the lack of enhanced weight gain in $t i s 7^{\text {tg }} \mathrm{vs.} \mathrm{WT} \mathrm{mice} \mathrm{post-resection} \mathrm{(Fig.}$ 7). However it is likely that additional mechanisms play a role; for example, adverse effects on the transport of other amino acids or peptides may also contribute to this phenotype. Although humans utilize the peptide transporter PepT1 to transport dipeptides and thus do not become protein deficient in the setting of reduced amino acid transport as in Hartnup's disease, mice have substantial reductions in body weight and lean body mass when amino acid transport is reduced [18]. For example mice in which the neutral amino acid transporter SCL6A19 is deleted [18], have reduced body weight and lean body mass. Our studies suggest that reduced proline uptake from the diet may affect the synthesis of key muscle proteins.

Expression of activated serine and threonine kinase SGK1 was markedly decreased in the transgenic jejunum and ileum. Activated SGK1 regulates ion channels, carriers and transporters, including the neutral amino acid transporter SLC6A19 (also known as B(0) AT1 [25], the glucose transporter SGLT and uniporters Glut1 and Glut4 [31]. SGK1 regulates transporter activity directly by phosphorylation, or by prevention of ubiquitination and degradation that enhances cell surface retention of carriers [19]. SGK1 has been shown to regulate SLC6A19 activity by increasing its cell surface expression via inhibition of ubiquitin ligase mediated degradation [25]. However, SGK1 appears to be required for activated transport, in response to factors such as glucocorticoids or inflammation, and not for basal transporter activity. Its effects on SGLT1 and SLC6A19 activity are only found in the setting of increased transporter activity induced by cellular stress or glucocorticoid excess [32]. For example, basal activities of SGLT1 and NHE3 are identical in the intestine of the SGK1 knockout intestine compared to WT before but are significantly different after exposure to dexamethasone [32]. Our experiments were performed in non-stressed conditions without growth factors or glucocorticoid exposure. Thus, despite the reduction in activated SGK1 levels, we did not observe a reduction in cell surface expression of SLC6A19 or SGLT1. However, a modest decrease in cell surface expression of the IMINO transporter SLC6A20 was detected, suggesting that basal cell surface expression of SLC6A20 may be more dependent upon activated SGK1. SLC6A20 mutation has been implicated as a cause of iminoglycinuria [17]. However, the modest observed reduction in SLC6A20 cell surface expression does not fully explain a $50 \%$ reduction in proline transport, suggesting additional mechanisms that have yet to be explored. For example, SGK1 may also regulate proline transport directly by affecting transporter phosphorylation. Future experiments will be directed to further elucidate the underlying mechanism(s).

The mechanisms by which SGK1 expression is inhibited by tis7 overexpression are unclear. SGK1 is ubiquitously expressed and its activity is induced by hormones such as glucocorticoids and cell stress [19]. SGK1 is also activated by insulin and growth factors such as the insulin-like growth factor-1 via phosphatidylinositol 3-kinase, the 3-phosphoinositidedependent kinase [33], and mammalian target of rapamycin [31]. We previously observed that serum IGF-1 levels in tis $7^{\text {tg }}$ mice are significantly lower than in WT littermates [11], suggesting a potential mechanism for the reduced expression of activated SGK1 in the tis $7^{\text {tg }}$ intestinal mucosa compared to WT littermates. Alternatively, tis7 may inhibit SGK1 via its cell-type- and target gene-specific function as a transcriptional coactivator [34, 35] or corepressor $[10,36]$. Future studies will address whether tis7 interacts with the SIN3 histone deacetylase complex to inhibit SGK1 expression, as it does to regulate cellular retinoic acid binding protein II expression in mammary epithelium [10].

Therapies that are directed towards enhancing nutrient and calorie absorption in short bowel syndrome are lacking. In these studies we sought to determine whether tis7 overexpression might provide a nutrient absorptive advantage post resection. Despite our previous observation that mice with intestinal tis7 overexpression have increased gut 
triglyceride absorption and accelerated weight gain when fed a high saturated fat diet, tis $7^{\text {tg }}$ and WT mice had similar weight gain after 50\% small bowel resection (Fig. 7). It is possible that enhanced triglyceride absorption driven by tis7 overexpression in the remaining intestine could not compensate for the massive loss of absorptive function following $50 \%$ resection. Alternatively, the reduction in proline transport, which is further decreased following massive resection, may explain the lack of enhanced weight gain. Additional studies in which more limited resections are performed may help clarify these issues.

In summary, tis7 regulates multiple intestinal nutrient absorptive pathways. Our previous studies showed that enterocytic tis7 overexpression resulted in increased adiposity but decreased lean body mass, similar to the metabolic phenotype of patients with short bowel syndrome who are fed with parenteral nutrition [11]. These studies provide a potential explanation for reduced lean body mass in these mice, although it is likely that tis7 overexpression affects absorption of other amino acids as well. Reduced proline absorption in the intestinal tis $7^{\text {tg }}$ mouse is associated with decreased apical cell surface expression of SLC6A20, which is likely mediated by reduced SGK1 expression, a key regulator of nutrient transporters and channels. The tis $7^{\text {tg }}$ mouse thus represents a novel model to study the metabolic pathogenesis of short bowel syndrome.

\section{Acknowledgements}

This research was supported by NIH R01DK106382, R01DK46122, R01DK61216 (DCR, MSL), the Digestive Diseases Research Core Center DK52574, the Siteman Cancer Center SIP 8073-88, and NIH Ruth L. Kirschstein National Research Service Award T32 DK077653 (AG). We thank Drs. Kumar Bishnupuri, Ramon Jin and Brian Dieckgraefe for technical advice.

\section{Disclosure Statement}

Authors have no disclosures.

\section{References}

1 Tappenden KA: Intestinal adaptation following resection. JPEN J Parenter Enteral Nutr 2014;38:23S-31S.

2 Levin MS, Rubin DC: Intestinal adaptation: the biology of the intestinal response to resection and disease; in Langnas AN, Goulet O, Quigley EMM, Tappenden KA (eds): Intestinal Failure: Diagnosis, Management and Transplantation. Malden, MA 02148, Blackwell, 2008, pp 45-54.

3 Abu-Elmagd K: The concept of gut rehabilitation and the future of visceral transplantation. Nat Rev Gastroenterol Hepatol 2015;12:108-120.

4 Vipperla K, O'Keefe SJ: Targeted therapy of short bowel syndrome with teduglutide: the new kid on the block. Clin Exp Gastroenterol 2014;7:489-495.

5 Sun RC, Choi PM, Diaz-Miron J, Sommovilla J, Guo J, Erwin DR, Warner BW: High-protein diet improves postoperative weight gain after massive small-bowel resection. J Gastrointest Surg 2015; 19:451-457.

6 Buchman AL: Short bowel syndrome. Clin Gastroenterol Hepatol 2005;3:1066-1070.

7 Garcia A, Wakeman D, Lu J, Rowley C, Geisman T, Butler C, Bala S, Swietlicki EA, Warner BW, Levin MS, Rubin DC: Tis7 deletion reduces survival and induces intestinal anastomotic inflammation and obstruction in high fat diet fed-mice with short bowel syndrome. Am J Physiol Gastrointest Liver Physiol 2014;307:G642-G654.

8 Yu C, Jiang S, Lu J, Coughlin CC, Wang Y, Swietlicki EA, Wang L, Vietor I, Huber LA, Cikes D, Coleman T, Xie Y, Semenkovich CF, Davidson NO, Levin MS, Rubin DC: Deletion of Tis7 protects mice from high-fat dietinduced weight gain and blunts the intestinal adaptive response postresection. J Nutr 2010;140:19071914.

9 Vietor I, Huber LA: Role of TIS7 family of transcriptional regulators in differentiation and regeneration. Differentiation 2007;75:891-897.

10 Vietor I, Vadivelu SK, Wick N, Hoffman R, Cotten M, Seiser C, Fialka I, Wunderlich W, Haase A, Korinkova G, Brosch G, Huber LA: TIS7 interacts with the mammalian SIN3 histone deacetylase complex in epithelial cells. EMBO J 2002;21:4621-4631.

11 Wang Y, Iordanov H, Swietlicki EA, Wang L, Fritsch C, Coleman T, Semenkovich CF, Levin MS, Rubin 


\section{Cellular Physiology Cell Physiol Biochem 2016;38:1532-1543

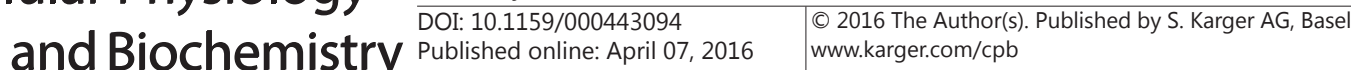

Lu et al.: Reduced Proline Absorption in Tis7 Transgenic Mice

DC: Targeted Intestinal Overexpression of the Immediate Early Gene tis7 in Transgenic Mice Increases Triglyceride Absorption and Adiposity. J Biol Chem 2005;280:34764-34775.

12 Antalis TM, Shea-Donohue T, Vogel SN, Sears C, Fasano A: Mechanisms of disease: protease functions in intestinal mucosal pathobiology. Nat Clin Pract Gastroenterol Hepatol 2007;4:393-402.

13 Leturque A, Brot-Laroche E, Le Gall M: Carbohydrate intake. Prog Mol Biol Transl Sci 2012;108:113-127.

14 Karasov WH, Douglas AE: Comparative digestive physiology. Compr Physiol 2013;3:741-783.

15 Karasov WH, Diamond JM: A simple method for measuring intestinal solute uptake in vitro. J Comp Physiol 1983;152:105-116.

16 Wright EM, Loo DD, Hirayama BA: Biology of human sodium glucose transporters. Physiol Rev 2011;91:733-794.

17 Bröer S: Amino acid transport across mammalian intestinal and renal epithelia. Physiol Rev 2008;88:249286.

18 Bröer A, Juelich T, Vanslambrouck JM, Tietze N, Solomon PS, Holst J, Bailey CG, Rasko JE, Bröer S: Impaired nutrient signaling and body weight control in a $\mathrm{Na}+$ neutral amino acid cotransporter (Slc6a19)-deficient mouse. J Biol Chem 2011;286:26638-26651.

19 Lang F, Böhmer C, Palmada M, Seebohm G, Strutz-Seebohm N, Vallon V: (Patho)physiological significance of the serum- and glucocorticoid-inducible kinase isoforms. Physiol Rev 2006;86:1151-1178.

20 Tang Y, Swietlicki EA, Jiang S, Buhman KK, Davidson NO, Burkly LC, Levin MS, Rubin DC: Increased apoptosis and accelerated epithelial migration following inhibition of hedgehog signaling in adaptive small bowel postresection. Am J Physiol Gastrointest Liver Physiol 2006;290:G1280-G1288.

21 Iqbal CW, Qandeel HG, Zheng Y, Duenes JA, Sarr MG: Mechanisms of Ileal Adaptation for Glucose Absorption after Proximal-Based Small Bowel Resection. J Gastrointest Surg 2008;12:1854-1865.

22 Schmittgen TD, KJ Livak: Analyzing real-time PCR data by the comparative Ст method. Nature Protocols 2008;3:1101-1108.

23 Ameen N, Apodaca G: Defective CFTR apical endocytosis and enterocyte brush border in myosin VIdeficient mice. Traffic 2007;8:998-1006.

24 Au A, Gupta A, Schembri P, Cheeseman CI: Rapid insertion of GLUT2 into the rat jejunal brush-border membrane promoted by glucagon-like peptide 2. Biochem J 2002;367:247-254.

25 Bohmer C, Sopjani M, Klaus F, Lindner R, Laufer J, Jeyaraj S, Lang F, Palmada M: The serum and glucocorticoid inducible kinases SGK1-3 stimulate the neutral amino acid transporter SLC6A19. Cell Physiol Biochem 2010;25:723-732.

26 Kowalczuk S, Bröer A, Tietze N, Vanslambrouck JM, Rasko JE, Bröer S: A protein complex in the brushborder membrane explains a Hartnup disorder allele. FASEB J 2008;22:2880-2887.

27 Rexhepaj R, Grahammer F, Völkl H, Remy C, Wagner CA, Sandulache D, Artunc F, Henke G, Nammi S, Capasso G, Alessi DR, Lang F: Reduced intestinal and renal amino acid transport in PDK1 hypomorphic mice. FASEB J 2006;20:2214-2222.

28 http://www.ncbi.nlm.nih.gov/gene/20393

29 Simon P, Schneck M, Hochstetter T, Koutsouki E, Mittelbronn M, Merseburger A, Weigert C, Niess A, Lang F: Differential regulation of serum- and glucocorticoid-inducible kinase 1 (SGK1) splice variants based on alternative initiation of transcription. Cell Physiol Biochem 2007;20:715-728.

30 Raikwar NS, Liu KZ, Thomas CP: A regulated NH2-terminal Sgk1 variant with enhanced function is expressed in the collecting duct. Am J Physiol Renal Physiol 2012;303:F1527-F1533.

31 Lang F, Stournaras C: Serum and glucocorticoid inducible kinase, metabolic syndrome, inflammation, and tumor growth. Hormones (Athens) 2013;12:160-171.

32 Grahammer F, Henke G, Sandu C, Rexhepaj R, Hussain A, Friedrich B, Risler T, Metzger M, Just L, Skutella T, Wulff P, Kuhl D, Lang F: Intestinal function of gene-targeted mice lacking serum- and glucocorticoidinducible kinase 1. Am J Physiol Gastrointest Liver Physiol 2006;290:G1114-G1123.

33 Kobayashi T, Cohen P: Activation of serum- and glucocorticoid-regulated protein kinase by agonists that activate phosphatidylinositide 3-kinase is mediated by 3-phosphoinositide-dependent protein kinase-1 (PDK1) and PDK2. Biochem J 1999;339:319-328.

34 Micheli L, Leonardi L, Conti F, Buanne P, Canu N, Caruso M, Tirone F: PC4 coactivates MyoD by relieving the histone deacetylase 4-mediated inhibition of myocyte enhancer factor 2C. Mol Cell Biol 2005;25:22422259.

35 Micheli L, Leonardi L, Conti F, Maresca G, Colazingari S, Mattei E, Lira SA, Farioli-Vecchioli S, Caruso M, Tirone F: PC4/Tis7/IFRD1 stimulates skeletal muscle regeneration and is involved in myoblast differentiation as a regulator of MyoD and NF-kappaB. J Biol Chem 2011;286:5691-5707.

36 Vietor I, Kurzbauer R, Brosch G, Huber LA: TIS7 regulation of the beta-catenin/Tcf-4 target gene osteopontin (OPN) is histone deacetylase-dependent. J Biol Chem 2005;280:39795-39801. 